\title{
SEGMENTO CONTÁBIL E MORTALIDADE DE EMPRESAS: FATORES INTERVENIENTES
}

Samuel Martins ${ }^{1}$

Glaucia Vale ${ }^{1}$

Simone Costa Nunes ${ }^{1}$

${ }^{1}$ Pontifícia Universidade Católica de Minas Gerais - PUC Minas 


\section{SEGMENTO CONTÁBIL E MORTALIDADE DE EMPRESAS: FATORES INTERVENIENTES}

Resumo: Empresas de contabilidade, cuja função seria de ajudar empreendimentos de outros setores, garantindo sobrevivência e desenvolvimento desses, não se encontram imunes ao processo de extinção. Muitas delas encerram, precocemente, suas atividades, lançando por terra recursos, empregos e sonhos. Apesar da importância do tema sobrevivência e mortalidade empresarial, não existe literatura específica para o segmento contábil. O presente artigo, ao lançar mão da literatura, por um lado, sobre características e atributos de um profissional/empresa contábil e, por outro, sobre sobrevivência e mortalidade de empresas, em geral, elabora e testa, em uma pesquisa junto a 4 empresas na RMBH, um modelo teórico de análise, adaptado ao segmento. Os resultados sugerem que os fatores motivação, dedicação, experiência no ramo, redes de contato e a formação prévia influenciam fortemente a maneira como os empreendedores tocam seus negócios e atuam no mercado; e, também, influenciam a capacidade de sobrevivência e mortalidade de suas empresas.

Palavras-chave: Sobrevivência. Mortalidade. Contador. Empresa de Contabilidade.

\section{$1 \quad$ Introdução}

Muitos profissionais da área de contabilidade fazem opção de abrir suas próprias empresas, em vez de ingressarem em uma companhia já constituída ou em departamentos de contabilidade de organizações maiores. Existem hoje, no Brasil, cerca de 67 mil empresas prestadoras de serviços contábeis (EPSC), atuando em diferentes segmentos do mercado, visando atender necessidades e demandas de outras empresas nas áreas de escrituração contábil/fiscal, obrigações trabalhistas e outras (Conselho Federal de Contabilidade [CFC], 2019).

A procura por empresas de contabilidade parece aumentar, sobretudo, em contexto de crise econômica, quando companhias de outros segmentos buscam ajuda, visando aperfeiçoar sistemas de controle, acessar financiamentos, regularizar pendências fiscais e trabalhistas, etc. Dessa maneira, as EPSC assumem, muitas vezes, papel fundamental para a estabilidade, sobrevivência ou o fortalecimento de outras organizações (Walter, Cruz \& Espejo, 2011). No entanto, por mais que possam contribuir na melhoria do desempenho das empresas às quais auxiliam, muitas ESPC enfrentam suas próprias dificuldades e carências internas, que comprometem seu desempenho e sua sobrevivência no mercado.

O tema da sobrevivência e mortalidade de empresas, em geral, é de importância estratégica no mundo de hoje. Com efeito, cada unidade produtiva que fracassa acaba lançando por terra recursos, sonhos e empregos. Diferentes estudos vêm procurando identificar os fatores condicionantes da mortalidade de empresas em geral (Vale \& Guimarães, 2010; Ferreira, Oliva, Grisi, \& Lima, 2012; Serviço de Apoio às Micro e Pequenas Empresas [Sebrae], 2016a). Entre os fatores eventualmente capazes de ajudar no fortalecimento das empresas (evitando a mortalidade), encontra-se a presença de bom serviço contábil. Segundo dados do Sebrae (2016b), 68\% das empresas com menos de dois anos de existência no Brasil tomam decisões recorrendo à ajuda/apoio de uma empresa de contabilidade ou de um contador. 
Embora as EPSC possam ajudar no fortalecimento das empresas, em geral, elas próprias não se encontram imunes ao processo de extinção. Segundo dados do Sebrae (2016a), enquanto as taxas de sobrevivência das MPE brasileiras com até dois anos de idade saltaram de $54,2 \%$ entre $2008-2010$ para $76,6 \%$ no período $2012-2014$, no segmento contábil elas permaneceram praticamente estáveis, da ordem de $76 \%$, o que indica uma taxa de mortalidade relativamente elevada, de aproximadamente $24 \%$. Ou seja, para cada conjunto de 100 empresas contábeis que surgem, 24 delas deixam de existir em menos de dois anos.

A elevada mortalidade de empresas de contabilidade parece contradizer a própria natureza desses empreendimentos, o que torna relevante a busca pela compreensão dos fatores ou motivos intervenientes no processo. Apesar da importância do tema, levantamentos realizados em periódicos nacionais e internacionais de Administração e Contabilidade disponíveis no Portal de Periódicos CAPES/MEC e Portal de Periódicos Spell, tais como o Journal of Accounting and Economics e o The International Journal of Accounting, nos últimos dez anos, constataram a grande lacuna existente na área. Não foi identificada nenhuma pesquisa no campo referente à temática central deste estudo.

O presente trabalho se insere neste contexto. Cumpre, nesse momento, a missão de abrir as portas para uma primeira investigação e reflexão sobre os fatores e as causas específicos de sobrevivência e mortalidade de empresas no segmento contábil. Para isso, aborda, na segunda seção (referencial teórico) o tema do perfil/características do segmento contábil, antes de tratar dos fatores de sobrevivência e mortalidade de empresas, em geral, como explorado na literatura corrente. O artigo é concluído com a proposição de modelo teórico integrado para a pesquisa. Na terceira seção (metodologia e resultados obtidos), ele apresenta os casos de quatro empresas de contabilidade pesquisadas (duas ativas e duas que encerraram suas atividades), localizadas na região metropolitana de Belo Horizonte. Concluise (considerações finais) que fatores como motivação, dedicação, experiência prévia no segmento e empresarial, redes de contato, formação, gestão, a variedade de serviços ofertados, além da natureza da concorrência e do perfil dos clientes, são fatores que influenciam na sobrevivência empresarial.

\section{$2 \quad$ Referencial Teórico}

As empresas de contabilidade apresentam certas particularidades em relação àquelas inseridas em outros segmentos. Uma delas seria, como citado por Michieletto, Romão, Urvanavicius e Lima (2010), uma forte identidade entre o profissional, o cliente e a atividade, requerendo, além de um perfil profissional adequado, também um modelo de gestão bastante peculiar. Grande parte do sucesso (ou fracasso) da empresa no mercado pode ser imputado ao perfil e às características de seu proprietário, pelos elementos enraizados desde a sua formação profissional.

Para Peleias, Segreti, Silva e Chirotto (2007) o profissional contábil deve possuir visão mais competitiva de negócio, ser capaz de oferecer produtos/serviços diferenciados e ajustados às necessidades de seus clientes, além de saber lidar com fatores contingenciais, ter noção de ambiente e estratégia e boa compreensão do segmento empresarial onde atuam (Walter, Cruz, Espejo, \& Gassner, 2009). Ao mesmo tempo, deve ser também capaz de criar uma imagem positiva, reconhecida no mercado (Walter, Cruz, \& Espejo, 2011). 
Estudos sobre o desenvolvimento profissional desenvolvidos por Bujaki, Durocher, Brouard, Leighann e Pyper, (2015), Sithole (2015), Madruga, Colossi e Biazus (2016), Fiolleau e Kaplan (2017), por exemplo, falam da necessidade de mudanças no perfil do profissional corrente adotando uma postura ética. Outros, por sua vez, citam a necessidade do domínio de técnicas fundamentais para o desenvolvimento do negócio, tais como ferramentas de marketing e técnicas de gestão (Peleias, Castro Júnior, Cunha, \& Segreti, 2011; Peleias, Lourenço, Peters, \& Lavarda, 2015).

Cardoso (2006), no seu estudo empírico sobre o perfil do profissional do segmento, identifica 13 competências requeridas para um profissional contábil, sendo: conhecimentos técnicos em contabilidade e finanças; conhecimento dos aspectos legais; habilidades com o manuseio de ferramentas de controle; capacidade de comunicar; empreender; traçar estratégias; ser dotado de integridade e confiança; capacidade em negociar; habilidade com técnicas de gestão;gerenciamento de informações; saber ouvir eficazmente; ter bom atendimento; e, capacidade de atuar em equipes. Do ponto de vista do autor, a análise dessas competências poderia ser melhor compreendida se essas fossem classificadas em quatro grandes classes ou categorias, sendo: específicas; associadas à conduta e administração; associadas ao gerenciamento da informação; e, de comunicação.

O Quadro 1 busca, dentro das quatro categorias sugeridas por Cardoso (2006), agregar atributos e características frequentemente citados na literatura e julgados importantes para o profissional ou empresa de contabilidade.

Quadro 1 - Classificação dos atributos e características dos contadores e empresas de contabilidade segundo os estudos analisados

\begin{tabular}{|c|c|}
\hline Classes Genéricas & Atributos e Características \\
\hline Específicas & $\begin{array}{c}\text { Conhecimentos técnicos abrangentes; Experiência; Necessidade de desenvolvimento; } \\
\text { Necessidade de realização; Qualidade dos produtos e serviços. }\end{array}$ \\
\hline $\begin{array}{c}\text { Conduta e } \\
\text { Administração }\end{array}$ & $\begin{array}{c}\text { Agilidade; Capacidade de gestão e controle; Capacidade de Organização; Personalidade; } \\
\text { Postura profissional; Capacidade de inovação; Competência; Confiança; Capacidade de } \\
\text { síntese; Dedicação; Iniciativa; Intuiça; Motivação; Perseverança Persistência; } \\
\text { Capacidade de liderança; Postura ética; Propensão a riscos calculados. }\end{array}$ \\
\hline $\begin{array}{c}\text { Gerenciamento da } \\
\text { informação }\end{array}$ & Capacidade de negociação; Habilidades tecnológicas; Capacidade de gestão. \\
\hline Comunicação & Capacidade de interação; Capacidade de comunicação; Redes de contato. \\
\hline
\end{tabular}
Fonte: Elaboração própria.

No contexto empresarial, o sucesso é associado à eficácia, ou seja, à capacidade da empresa/empreendedor em obter bons resultados no mercado. No entanto, evidências sugerem que o fracasso muitas vezes tende a ser o destino mais provável (Thornhill \& Amit, 2003) e que todos os empresários terão que enfrentar o fracasso em algum momento do empreendimento (Pretorius, 2009).

A busca dos fatores condicionantes, que levam empresas à extinção/mortalidade, tem atraído a atenção de inúmeros pesquisadores em várias partes do mundo (Vale \& Guimarães, 2010; Sebrae, 2016a; Zammel \& Khoufi, 2016; Mayr, Mitter, \& Aichmayr, 2017, entre outros). Muitos deles procuram elencar diferentes conjuntos de fatores e verificar em que medida cada um deles poderia divergir, comparando-se empresas ativas com extintas. Existe certo consenso por parte dos autores de que a sobrevivência ou a mortalidade é consequência 
da ação simultânea de mais de um fator. Torna-se um grande desafio conhecer e compreender todos eles.

No contexto desse trabalho foram analisados 32 artigos derivados de pesquisas realizadas no Brasil e no exterior sobre o tema de interesse. Entre os principais fatores de sobrevivência e mortalidade identificados na literatura, encontram-se: habilidade de gestão (23 citações), controle financeiro (16 citações), planejamento (16 citações), natureza da concorrência (14 citações), uso de técnicas de marketing (12 citações), acesso ao crédito (11 citações), situação econômica do mercado e apoio governamental (10 citações), experiência anterior (9 citações), recursos disponíveis (8 citações), conhecimento do empreendedor (8 citações), visão empreendedora (8 citações), carga tributária (7 citações), formação acadêmica (7 citações), redes de relacionamento (7 citações).

Ferreira et al. (2012), ao analisar diferentes estudos sobre o tema, acabaram por propor que os fatores de sobrevivência e mortalidade de empresas fossem agrupados em três grandes categorias, de maneira a permitir melhor análise e interpretação do fenômeno. São elas: inerentes ao empreendedor, inerentes ao negócio e inerentes ao ambiente externo da empresa. Ao se alinhar os diferentes fatores citados de maneira geral na literatura dentro das três grandes categorias propostas por Ferreira et al. (2012), depreende-se o Quadro 2, a seguir.

\section{Quadro 2 - Classificação dos fatores de sobrevivência e mortalidade de empresas segundo as} três categorias

\begin{tabular}{|l|l|}
\hline \multicolumn{1}{|c|}{$\begin{array}{c}\text { Categorias } \\
\text { Genéricas }\end{array}$} & \multicolumn{1}{c|}{ Fatores elencados e classificados } \\
\hline $\begin{array}{l}\text { Indivíduo } \\
\text { (Empreendedor) }\end{array}$ & $\begin{array}{l}\text { Características pessoais; Experiência profissional; Experiência com gestão e e } \\
\text { empresarial; Formação; Faixa etária do empreendedor; Motivação; Personalidade; } \\
\text { Propensão a riscos; Redes de relacionamentos. }\end{array}$ \\
\hline $\begin{array}{l}\text { Empreendimento } \\
\text { (Negócio) }\end{array}$ & $\begin{array}{l}\text { Capacidade de inovação; Idade da empresa; Localização; Mão de obra qualificada; } \\
\text { Natureza da carteira de clientes; Parcerias corporativas; Produtos e serviços ofertados; } \\
\text { Qualidade dos produtos e serviços ofertados; Rentabilidade do negócio; Suporte ao } \\
\text { negócio; Utilização de ferramentas de gestão. }\end{array}$ \\
\hline Ambiente (setor) & $\begin{array}{l}\text { Acesso às fontes de recursos; Carga tributária; Gênero; Natureza da concorrência; } \\
\text { Perfil do Cliente; Política econômica; Políticas Públicas Regulamentação do Setor; } \\
\text { Roubo e corrupção; Segmento do mercado. }\end{array}$ \\
\hline
\end{tabular}

\section{Fonte: Elaboração própria.}

Lançando mão da literatura sobre atributos/características dos profissionais de contabilidade e sobre os fatores condicionantes de sobrevivência e mortalidade empresarial, apresenta-se, a seguir, a construção do modelo teórico proposto.

Como visto anteriormente, os atributos e as características considerados importantes para o profissional de contabilidade foram agrupados em quatro grupos (Cardoso, 2006). No nosso entendimento, tais atributos/características poderiam ser agrupados em apenas duas grandes classes. A primeira, associada a Atributos/Características Específicas de Conduta e Administração, abarcaria conhecimentos técnicos desejáveis e essenciais para o exercício profissional, além das qualidades pessoais daí advindas, como agir ético, ser íntegro e confiável, com visão empreendedora, motivacional, entre outras. A segunda, associada a Atributos/Características de Comunicação e Gerenciamento da Informação, estaria relacionada à capacidade do profissional em entender e se fazer entender, identificar e utilizar 
das informações do contexto profissional empresarial, incluindo sua capacidade em criar e manter redes de contato e relacionamento, de parcerias, além de sua capacidade de lançar mão de técnicas de gestão e planejamento.

Comparando-se as categorias de atributos/características do profissional com as categorias de fatores de sobrevivência/mortalidade de empresas, é possível identificar forte sintonia entre esses, conforme apresentado no Quadro 3, a seguir.

Quadro 3 - Associação entre fatores de sobrevivência/mortalidade e atributos/características do contador-empreendedor na EPSC

\begin{tabular}{|l|l|l|}
\hline Categoria & Fator & Atributo/Característica \\
\hline \multirow{4}{*}{$\begin{array}{l}\text { Empreendedor } \\
\text { (Indivíduo) }\end{array}$} & Características pessoais & Integridade e Confiança \\
\cline { 2 - 3 } & Experiência & Motivação \\
\cline { 2 - 3 } & Redes de contato & Com gestão/empresarial \\
\cline { 2 - 3 } $\begin{array}{l}\text { Empreendimento } \\
\text { (Negócio) }\end{array}$ & Formação & Relações pessoais e capacidade de interação \\
\cline { 2 - 3 } & Gestão & Conhecimentos e habilidades \\
\hline \multirow{4}{*}{ Ambiente (setor) } & Serviços ofertados & Agilidade e Pontualidade \\
\cline { 2 - 3 } & Mão de obra & Qualidade \\
\cline { 2 - 3 } & Perfil do cliente \\
\cline { 2 - 3 } & Polureza da concorrência \\
\hline
\end{tabular}

Fonte: Elaboração própria.

No que diz respeito à categoria Empreendedor (indivíduo), observa-se que se associam fatores condicionantes da sobrevivência ou mortalidade, incluindo: (a) as características pessoais, relacionadas ao modo de agir do empreendedor, como integridade e confiança, a motivação que segundo Matias e Martins (2012) motiva e impulsiona a necessidade de realização; (b) à experiência, que motiva e condiciona o profissional a constituir empresas (Testas \& Moreira, 2014); (c) às redes de contatos, associado à capacidade do empreendedor de usufruir de benefícios oriundos de suas conexões sociais (Vale \& Guimarães, 2010); e (d) a formação, constituindo processo em que são desenvolvidas e moldadas características como o caráter, valores, integridade moral, honestidade, força de vontade e cidadania (Madruga, Colossi, \& Biazus, 2016).

$\mathrm{Na}$ categoria Empreendimento (negócio), foram identificados que os fatores mais propensos a representarem o sucesso ou o fracasso em uma EPSC seriam (e) o estilo de gestão, que Macedo, Nóbrega, Queiroz e Whebber (2012) associam à maneira de agir do proprietário, que culmina a criação de uma identidade organizacional e na imagem da empresa no mercado; (f) os tipos de produtos/serviços ofertados, que segundo estudos do Sebrae (2016b), faz-se necessária a diversificação por meio da busca de novas possibilidades comerciais capazes de agregar maior valor ao negócio; e (g) a natureza da mão de obra, que Peleias et al. (2015) afirmam influenciar na qualidade percebida e nos clientes de uma empresa de contabilidade, requerendo do profissional conhecimentos adequados à sua atuação e qualificação.

A categoria Ambiente (setor) relaciona-se ao contexto externo do negócio. Os fatores identificados, e podem impactar no sucesso de uma EPSC seriam (h) o perfil do cliente, 
relacionado ao tipo de empresa (cliente ou nicho de mercado) explorado; (i) a natureza da concorrência, que para o segmento contábil Rodrigues e Lemos (2009) está associado aos aspectos éticos que envolvem as condutas profissionais; e (j) as políticas públicas que, Machado, Azevedo e Silva (2007) e Justino e Tenngeh (2016) apontam da necessidade de os entes públicos criarem mecanismos que efetivamente beneficiem os pequenos negócios, característica de uma EPSC.

A Figura 1 integra e incorpora as variáveis de interesse, procedentes das suas literaturas, no esboço de um modelo de análise à primeira vista mais ajustado a pesquisas na área de contabilidade.

Figura 1- Sugestão de Modelo Teórico

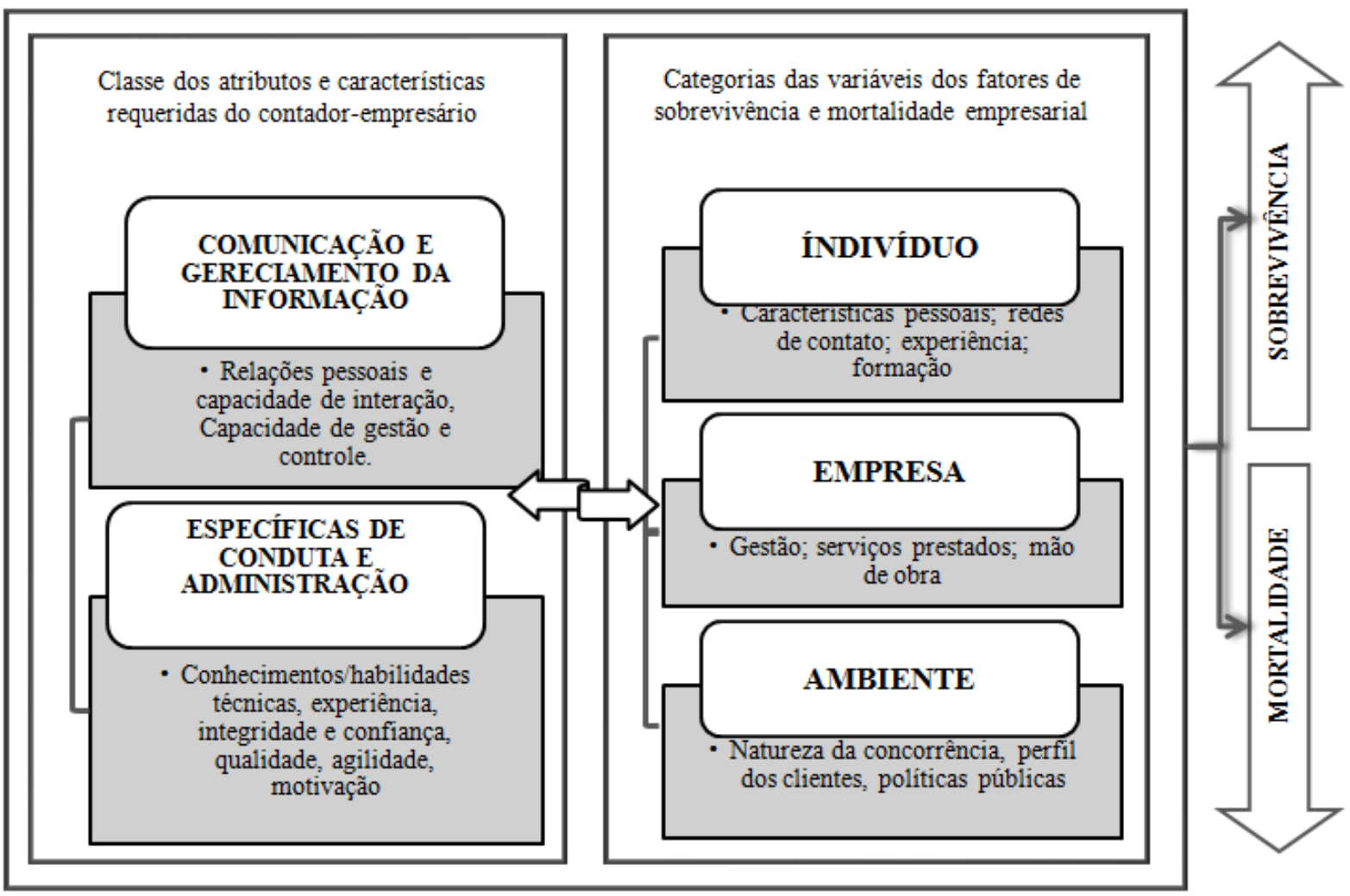

Fonte: Elaboração própria.

Observa-se no modelo proposto a convergência existente entre, de um lado, alguns dos atributos e competências considerados importantes para o profissional/empresa de contabilidade, e, de outro lado, os fatores considerados mais importantes de sobrevivência e mortalidade para efeito da presente pesquisa.

\section{$3 \quad$ Metodologia e resultados obtidos}

Para atender os objetivos propostos neste estudo descritivo, utilizou-se uma abordagem de natureza qualitativa (Triviños, 1987; Yin, 2010), recorrendo-se a entrevistas semiestruturadas junto a quatro empreendedores (sócios-proprietários) de EPSC de pequeno porte da Região Metropolitana de Belo Horizonte. Para efeito deste trabalho, considera-se 
empreendedor aquele que "cria uma empresa" (Gartner, 1989, p. 47). Observa-se que, no caso de unidades produtivas muito pequenas, a figura do empreendedor tende a se misturar com o próprio negócio ou empreendimento (Vale \& Guimarães, 2010; Hernández-Carrión, Camarero-Izquierdo, \& Gutiérrez-Cillán, 2017), o que torna possível analisar o empreendimento a partir da perspectiva de seu proprietário. Com efeito, salientam HernándezCarrión et al., (2017, p. 62) como, em pequenas empresas, "os empreendedores, suas características, recursos, relações, e estilo são inseparáveis do empreendimento". Por ocasião da coleta de dados, duas empresas encontravam-se ativas e duas extintas. A entrevista, cujo roteiro foi estruturado a partir dos cinco itens/parâmetros (dois de atributos/características e três de fatores) e seus respectivos subitens, como elencado no modelo, durou cerca de quatro horas. As evidências coletadas foram processadas e analisadas segundo tais parâmetros, permitindo-se chegar a conclusões baseadas em evidências empíricas (Yin, 2010). Visando preservar a privacidade dos quatro respondentes, adotou-se, no presente artigo, apenas a designação de casos 1, 2, 3 e 4, conforme a síntese das entrevistas que se segue.

A empresa 1, ativa, foi constituída em meados do ano de 2016 e A.H.C.M. é o único proprietário. Sua sede é no Vale do Sereno, em Nova Lima/Brasil. O proprietário A.H.C.M. tem 29 anos de idade, é bacharel em Ciências Contábeis, especialista em Auditoria e LLM em Direito Tributário. Atualmente está matriculado em dois outros programas: Gestão Financeira, Controladoria e Auditoria e, Gestão Estratégia e Gestão de Processos de Negócios. Os 11 anos de experiência no segmento contábil, como empregado e gestor, direcionaram-no para o segmento empresarial, inclusive como palestrante. A unidade pesquisada é a segunda EPSC do entrevistado. Ele destacou que por meio das experiências e formações foram desenvolvidas habilidades gerenciais que propiciam a gestão do seu negócio e dos serviços prestados. Quanto a estas expertises, reforçou que consegue "[...] aplicá-las também aos meus clientes; então, a mesma coisa que eu faço dentro da minha empresa, eu faço também nos clientes".

Segundo A.H.C.M., a criação da empresa foi motivada pelo desejo em criar um negócio que agregasse valor ao segmento contábil, relembrando ser algo não vislumbrado entre os sócios da antiga sociedade na qual era sócio. Ele ressaltou assim a incompatibilidade com o antigo negócio: "[...] devido a essa visão diferente da contabilidade e essa vontade de criar um serviço diferente do que existe no mercado". Para cumprir este propósito, destacou a sua dedicação intensa ao negócio, cujo objetivo principal é "[...] montar um serviço de tal forma que o meu cliente tenha em mim um SEBRAE particular".

As redes de contato foram utilizadas por A.H.C.M. para obter os clientes da empresa e primordiais em períodos de crise, facilitando assim o acesso a outros mercados. A esse respeito, ele disse que conseguiu "[...] criar outros relacionamentos com advogados, com administradores; e isso sim me traz clientes [...]", possibilitando manter o equilíbrio da carteira de clientes e das receitas.

A gestão da empresa é realizada por A.H.C.M. enfatizando ser o responsável por pensar "[...] em otimizar, aumentar lucratividade, aumentar o volume de clientes [...]". Como auxílio, a empresa mantém cinco empregados, disponibilizando incentivos para motivar e reter, e assim obter melhores resultados e qualidade nos serviços prestados.

A empresa presta serviços variados e personalizados de contabilidade, de consultoria em planejamento tributário e financeiro, e treinamentos empresariais, e possui, aproximadamente, 105 clientes ativos. $\mathrm{O}$ contador comentou tratar os clientes como novos projetos, analisando- 
os e oferecendo soluções satisfatórias. Neste sentido, relatou que "[...] é como se fosse um gerenciamento de projeto mesmo; eu pego, faço o mapeamento de necessidades, acompanho tudo, acompanho o cronograma até fechar [...]". Por não atuar com um perfil distinto de clientes, A.H.C.M. destacou pouco impacto das contrações do mercado, o que possibilitaria a melhor gestão da carteira e média de clientes, minimizando impactos da concorrência. Neste último destacou que embora haja "prostituição" no segmento, optou em manter parcerias e o compartilhamento de serviços.

Do ponto de vista das políticas econômicas e de regulamentação, entre outras, A.H.C.M. destacou obter oportunidades para ofertar serviços, essenciais para seu negócio.

O Caso 2, ativa, foi constituída em meados do ano de 2012 como empresa unilateral. Possui E.W. como o único proprietário. A sede da empresa está localizada no Bairro Planalto, na Região de Venda Nova (Região Metropolitana de Belo Horizonte [RMBH]/Brasil).

Aos 41 anos de idade, E.W. possui formação técnica em contabilidade, bacharelado em Ciências Contábeis, especialização em Auditoria, Controladoria, Mestrado em Administração de Empresas, e, atualmente, se encontra finalizando um MBA em Direito Tributário. E.W. reforçou que as suas "[...] especializações horizontais são [...] para atender melhor o cliente [...]" além de contribuir para a gestão de seus propósitos pessoais e empresariais. De acordo com os relatos, ele possui 23 anos de experiência no segmento contábil, como empregado e gestor, o que o direcionou para o segmento empresarial. A unidade pesquisada é a sua segunda EPSC.

Segundo E.W., as redes de contato foram essenciais para seu ingresso na profissão, e destacou que "[...] um contador que me deu assim aquele pontapé inicial [...]". Afirmou que as suas redes de contato são fontes de recursos, relatando: "[...] a gente nunca faz nada sozinho [...]". Nesse sentido, ele salientou que os seus contatos pessoais "[...] indicam serviços; que me procuram; e até mesmo a indicação dos meus clientes [...] hoje eu trabalho $100 \%$ por indicação".

A gestão da empresa é realizada por E.W., com o auxílio de seus quatro empregados. Para ele, a gestão é favorecida pela "busca contínua de inovação, tecnologia e qualificação". O contador-empresário atua nas atividades de maior especialização. No entanto, ele ponderou que a qualificação é o diferencial de uma EPSC. Para tanto justificou: "[...] se você tiver uma boa qualificação dos diretores e dos seus funcionários, você vai ter uma qualidade de vida!".

A empresa oferta serviços de consultoria contábil, tributária e trabalhista, gestão empresarial e de pessoas, porém personalizados, além dos serviços básicos que são terceirizados com um concorrente parceiro. A empresa possui 35 clientes na carteira, com um total de 76 unidades (matriz/filiais). A empresa atua somente com perfis de clientes optantes pelo Simples Nacional, concentrando no ramo de pequenas franquias de gêneros alimentícios, especialmente no segmento de chocolates e para pequenos negócios do ramo de construção civil. No entanto, o contador-empresário relatou que a crise vivida no país, entre os anos de 2012 e 2016, impactou negativamente a empresa, e, como alternativa para se manter no mercado, relatou: “[...] tive para diversificar [...]", referindo-se em flexibilizar os honorários e em ofertar novos serviços como mecanismo para preservar o negócio. Aliada à crise, E.W. relatou a concorrência do segmento que resulta em uma "[...] desordem do mercado contábil" referindo-se as políticas de preços praticadas. No seu caso, destacou a perda de clientes, mas disse manter parcerias para o compartilhamento de informações e serviços. 
No que se refere às políticas públicas, tais como políticas de regulamentação, econômicas, entre outras, o destaque está em não agregar valor aos serviços, e, de acordo com o empresário, os reflexos referem-se ao maior esforço para a realização dos serviços.

$\mathrm{O}$ caso 3 se trata de uma empresa extinta que era constituída sob a natureza jurídica limitada, composta por dois sócios e que iniciou suas atividades, efetivamente, em meados de 2012, com encerramento no final de 2017. A entrevistada foi a ex-proprietária M.J. A sede própria da empresa estava localizada na região central da cidade de Belo Horizonte/Brasil.

M. J. tem 48 anos de idade, formação em técnica administrativa e bacharelado em Ciências Contábeis. Ela relatou possuir 24 anos de experiência em cargos de coordenação administrativa e financeira. Em seus relatos destacou: “[...] praticamente trabalhei só em empresa privada e em áreas administrativas [...]". A EPSC foi o primeiro empreendimento da entrevistada, associando a experiência profissional ao negócio criado.

Os relatos de M. J. sugerem que a motivação em empreender na EPSC analisada se deu por questões pessoais. Assim ponderou: “[...] resolvi pela contabilidade mesmo porque era mais certo e o retorno mais breve". Para ela, empreender em uma EPSC foi uma alternativa para obter ganhos financeiros, como uma renda complementar, e com pouco investimento.

Relacionada à motivação pessoal para empreender, a entrevistada destacou a pouca dedicação dos sócios ao negócio, o que culminaria em problemas futuros à empresa. Ela comentou a falta de gestão e da carteira de clientes, gerando em reflexos financeiros; a dificuldade em ter acesso e reter a mão de obra; a perda de clientes e a dificuldade em obter novos clientes e serviços. Para ela, a situação ainda se agravou com a instabilidade econômica em um grande período, extinguindo ainda diversos clientes do ramo da construção civil.

M.J. relatou que dos contatos profissionais surgiram oportunidades de obter clientes. Ela comentou que "[...] praticamente não se consegue clientes sem que haja alguma indicação. Então usamos nossos contatos com outras empresas, com os funcionários que eram PJ [pessoa jurídica] [...]". No entanto, segundo ela, não utilizar outras fontes de contatos dificultou a busca de novas oportunidades, inclusive captar de novos clientes em momentos de crise.

A gestão da empresa era compartilhada entre os sócios, contudo, o enfoque estava na prestação dos serviços, relegando os aspectos internos do negócio. Quatro empregados auxiliavam na execução das atividades. Porém, M.J. destacou dificuldades na retenção de empregados, o que prejudicava as operações internas da empresa.

A empresa atuava na prestação de serviços básicos de contabilidade. Do ponto de vista da ex-proprietária, o enfoque era "[...] oferecer aquilo que ninguém gosta de fazer". Ela enumerou a perda de oportunidades de desenvolver nos serviços e captar novos clientes. $\mathrm{O}$ perfil dos clientes da empresa era formado por pequenos prestadores de serviços e empreendedores do setor de construção civil, optantes pelo Simples Nacional ou Lucro Presumido, principais segmentos de mercado impactados na economia no período entre os anos de 2014 e 2016, o que resultou em perda significativa de clientes. A empresa mantinha uma carteira fixa de, aproximadamente, 115 clientes e após, reduzida a menos de 20 clientes, teve perda financeira de mais de $80 \%$, tornando-se inviável a continuidade da empresa, diante dos problemas enfrentados, principalmente financeiros.

Ainda, M.J. comentou a perda de clientes para os concorrentes, acentuada no momento de crise. Ela ainda ponderou que as políticas governamentais, especialmente as tributárias, aumentaram os serviços da empresa, porém sem a geração de resultados financeiros. 
Por fim, o caso 4 trata-se de uma empresa constituída em 11/08/2014 e extinta voluntariamente em 31/01/2017, permanecendo no mercado por aproximadamente três anos. Sua sede era no bairro Jardim Leblon, na Região de Venda Nova (RMBH/Brasil).

A entrevistada, R.C. tem 35 anos e é bacharel em Ciências Contábeis. Segundo ela, sua trajetória profissional direcionou-a para o segmento contábil. Seu ingresso no mercado de trabalho foi "[...] aos 16 anos de menor aprendiz [...]. Era um escritório de uma construtora e [...] fiquei lá por quase oito anos e foi quando entrei na universidade para fazer contábeis". No segmento contábil, R.C. ingressou estagiária e assumiu funções específicas, lá permanecendo por cinco anos. Ela salientou que "[...] foi lá que aprendi mesmo a trabalhar com contabilidade na prática [...] só que quando o escritório é pequeno ou médio a gente aprende de tudo e acabei tomando gosto pela profissão mesmo". Posteriormente, essa experiência a direcionou a empreender.

Os relatos de R.C. sugerem que o ingresso no segmento relaciona-se à motivação pessoal, o "sonho em ser empresária" com uma "renda adicional". Mas ela ponderou ser essencial "[...] ter clientes bons, que pagam e que entendem do próprio negócio", reforçando o interesse financeiro. R.C. destacou que a saída do segmento empresarial se deu pela falta de dedicação ao negócio. Para ela o enfoque nos clientes e a ausência dos sócios no negócio restringiram a atenção a aspectos gerenciais e operacionais, relegados ao segundo plano.

As redes de contato de R.C. foram utilizadas para ingressar no segmento contábil, e para obter os primeiros clientes. Segundo ela "[...] o contador precisa desse tipo de contato, de ajuda e ele não faz isso tudo sozinho; todo mundo é desconfiado e contador tem fama de enrolado; então só quem conhece vem [...]". Porém, destacou que não foram desenvolvidas novas relações e parcerias, essenciais em momentos de crise, inibindo obter novos clientes.

A gestão da empresa ficava a cargo da entrevistada suportada pelas experiências profissionais, e relatou que "[...] tentava manter meus controles da minha empresa [...]". Ela destacou que a gestão foi deficitária, prejudicada pela ausência da dedicação dos sócios, cuja atenção enfocava o atendimento do cliente. A empresa contava com o auxílio de dois empregados. No entanto R.C. afirmou que os problemas financeiros inviabilizaram mantê-los.

A empresa dedicava-se à prestação de serviços básicos de contabilidade e de apoio a pessoas físicas. De acordo com R. C., o "[...] interesse era acrescentar mais serviço com o tempo". Os principais clientes da empresa eram pequenos comércios e empreendedores de construção civil, de contados conhecidos, no Simples Nacional e Lucro Presumido, e pessoas físicas. No entanto, “[...] não tinha um perfil específico e definido, geralmente, pequenos empresários e empresas, mas tomávamos o cuidado de não pegar cliente fora de nossa capacidade [...]". A empresa já manteve uma clientela de 67 clientes, mas que, na ocasião do fechamento, havia menos de três clientes, tornando inviável permanecer no segmento.

A dinâmica da concorrência foi prejudicial para o caso analisado. Assim, R.C. relatou que "[...] já tive casos que perdi clientes para outro contador que cobrava mais barato [...]". Ainda, ela destacou não ter desenvolvido parcerias e proximidades com os concorrentes. Adicionalmente, R.C. salientou que, por vezes, as políticas econômicas e tributárias são benéficas ao segmento, como fonte de oportunidades, ressaltando em especial auxilio às pessoas físicas. Porém, ela destacou o aumento do esforço na prestação dos serviços.

À luz das categorias genéricas de análise do fenômeno da sobrevivência e mortalidade empresarial propostas por Ferreira et al. (2012), os relatos dos casos estudados sugerem que 
as especificidades do indivíduo (empreendedor/contador-empresário) influenciaram nas especificidades do negócio (empresa de contabilidade) e no ambiente (segmento contábil), e mais bem explicariam a sobrevivência e mortalidade no segmento.

As evidências dão conta de que o conjunto das especificidades dos contadoresempresários influenciou diretamente no modo de gerir a empresa; de desenvolver e diversificar os serviços ofertados; de utilizar a mão de obra; na seleção e captação de clientes e; por fim, no modo de interação com a concorrência, acirrada para o segmento.

A partir das evidências empíricas coletadas, é possível apresentar os fatores de maior ou menor aderência ao modelo proposto, capazes de distinguir os dois grupos de empresas, conforme o Quadro 4. Para fins de identificação, esses fatores foram associados à influência positiva (+), negativa (-) ou neutra $(\mathrm{N})$. Esta associação, considerada a partir dos relatos dos contadores empresários, sugere que os fatores condicionantes abordados neste estudo, e os atributos e características esperados do contador-empresário, encontram-se enraizados em perfis pessoais e influenciam na maneira como cada um deles atua no segmento contábil.

Quadro 4 - Aderência dos fatores condicionantes e dos atributos/características individuais na sobrevivência ou mortalidade de empresas, nos casos analisados.

\begin{tabular}{|c|c|c|c|c|c|c|}
\hline \multirow{3}{*}{$\begin{array}{l}\text { Categorias } \\
\text { Genéricas }\end{array}$} & \multirow{3}{*}{ Fatores } & \multirow{3}{*}{ Atributos/Características } & \multicolumn{2}{|c|}{ Ativas } & \multicolumn{2}{|c|}{ Extintas } \\
\hline & & & Caso 1 & Caso 2 & Caso 3 & Caso 4 \\
\hline & & & $+/-/ \mathrm{N}$ & $+/-/ \mathrm{N}$ & $+/-/ \mathrm{N}$ & $+/-/ \mathrm{N}$ \\
\hline \multirow{5}{*}{$\begin{array}{l}\text { Empreendedor } \\
\text { (Indivíduo) }\end{array}$} & \multirow{2}{*}{$\begin{array}{c}\text { Características } \\
\text { pessoais }\end{array}$} & Integridade e confiança & + & + & + & + \\
\hline & & Motivação & + & + & - & - \\
\hline & Experiência & Com gestão e Empresarial & $\begin{array}{l}T \\
+\end{array}$ & + & - & - \\
\hline & Redes de contado & $\begin{array}{l}\text { Relações pessoais e } \\
\text { capacidade de interação }\end{array}$ & + & + & - & - \\
\hline & Formação & $\begin{array}{c}\text { Conhecimentos e } \\
\text { habilidades }\end{array}$ & + & + & - & - \\
\hline \multirow{4}{*}{$\begin{array}{l}\text { Empreendimento } \\
\text { (Negócio) }\end{array}$} & Gestão & Capacidade de Gestão & + & + & - & - \\
\hline & \multirow[b]{2}{*}{ Serviços ofertados } & Agilidade e pontualidade & + & + & + & + \\
\hline & & Qualidade & \pm & \pm & \pm & \pm \\
\hline & & o de obra & + & + & - & - \\
\hline \multirow{3}{*}{ Ambiente } & \multicolumn{2}{|c|}{ Natureza da concorrência } & $\mathrm{N}$ & - & - & - \\
\hline & \multicolumn{2}{|c|}{ Perfil do cliente } & + & - & - & - \\
\hline & \multicolumn{2}{|c|}{ Políticas públicas } & + & $\mathrm{N}$ & $\mathrm{N}$ & $\mathrm{N}$ \\
\hline
\end{tabular}

Fonte: Dados da pesquisa

\section{Considerações finais}

O modelo proposto mostrou-se bastante adequado para a análise do fenômeno no segmento de interesse. Fatores como motivação pessoal, falta de dedicação e experiência, redes de contato e natureza da formação inserem-se entre os mais relevantes.

Nos casos 1 e 2, que representam empresas ativas, os contadores-empresários constituíram as empresas motivados em oferecer serviços de geração de valor aos clientes e ao segmento. A dedicação intensa ao negócio suprimiu as carências internas, gerando ênfase na gestão e no planejamento. As experiências empresariais e no segmento foram associadas à 
ampla e diversificada formação, resultando em expertises e habilidades essenciais para o negócio, e úteis em momentos turbulentos, favorecendo desenvolver novos serviços e explorar outros nichos de mercado. As redes de contatos pessoais foram benéficas para a obtenção de clientes e a atuação em seu desenvolvimento possibilitou novas parcerias e a ampliação do ramo de atuação. A formação, a experiência e as redes de contatos foram relevantes, especialmente em momentos de crise, minimizando os impactos do mercado via oferta de novos serviços e captação de novos clientes.

Por outro lado, nos casos 3 e 4, representantes de empresas extintas, os contadoresempresários constituíram as empresas sob a motivação da segunda fonte de renda. Eles se dedicavam à atividade com o enfoque na prestação de serviços, relegando diversos aspectos internos e ambientais do negócio, tais como a gestão da empresa e os impactos do ambiente em momentos de instabilidade econômica vivida pelo país nos últimos anos. A pouca experiência profissional e empresarial, associada à formação básica, resultou em poucas expertises e habilidades na condução do negócio e em seus posicionamentos no mercado, inibindo o desenvolvimento de novos serviços; gerou ineficiência diante das perdas de clientes, associada à contração econômica e aos impactos da concorrência acirrada no segmento. Por sua vez, as redes de contato, embora utilizadas para obter os primeiros clientes, não foram desenvolvidas a fim de favorecer novas oportunidades, essenciais para o segmento, culminando em um fator-chave para a saída do ramo empresarial: a falta de clientes.

Embora haja outras variáveis no modelo proposto, os fatores trabalhados nesta pesquisa são os mais relevantes para a distinção entre empresas ativas e extintas. Como salientado por Shonesy e Gulbro (1998), concentrar-se em sucesso inevitavelmente faz inferir sobre as razões de fracasso, e vice-versa. Ao identificar fatores-chave de sucesso e, consequentemente de fracasso, ou vice-versa, o presente estudo fornece ao profissional da área um rico conjunto de informações e dados relevantes para análise e julgamento de sua própria atividade e das atividades de sua empresa. Ao mesmo tempo, deixa pronto um modelo de análise passível de ser adaptado e ajustado a diferentes investigações sobre o segmento de contabilidade.

Observa-se, no entanto, que esse campo é bastante vasto, exigindo diferentes abordagens e investigações. A própria pesquisa apresenta suas limitações, pois não permite generalização estatística e ampliação para todo o segmento de interesse. Neste sentido, sugerem-se novos estudos capazes de, por exemplo, investigar diferentes tipos de empresas contábeis, em diferentes mercados ou, então, capazes de avaliar o papel das redes de relacionamentos na criação e expansão de empresas na área, temas esses de grande importância para todo o segmento.

\section{Referências}

Bujaki, M. L.; Durocher, S.; Brouard, F.; Leighann, N. \& Pyper, R. (2015). The Diversity of 'Diversity' in Canadian Accounting Firm Recruitment Websites. Electronic Journal.

Cardoso, R. L. (2006). Competências do contador: um estudo empírico. (Tese de Doutorado). Faculdade de Economia, Administração e Contabilidade, Universidade de São Paulo, São Paulo/SP.

Conselho Federal de Contabilidade. (2019). Dados estatísticos: profissionais da contabilidade e organizações contábeis. Brasília: CFC. [Quantos Somos]. Recuperado a partir de http://www3.cfc.org.br/spw/crcs/ConselhoRegionalAtivo.aspx 
Ferreira, L. F. F.; Oliva, S. A.; Grisi, C. C. H.; \& Lima, A. F. (2012). Análise quantitativa sobre a mortalidade precoce de micro e pequenas empresas da cidade de São Paulo. Revista Gestão e Produção, São Carlos, v. 19, n. 4, p. 811-823.

Fiolleau, K.; \& Kaplan, S. E. (2017). Recognizing ethical issues: an examination of practicing industry accountants and accounting students. Journal of Business Ethics.

Gartner, W. B. (1989). Who is the entrepreneur? Is the wrong question. Entrepreneurship Theory and Practice, 47-68.

Hernández-Carrión, C.; Camarero-Izquierdo, C.; \& Gutiérrez-Cillán, J. (2017). Entrepreneurs' social capital and the economic performance of small businesses: The moderating role of competitive intensity and entrepreneurs' experience. Strategic Entrepreneurship Journal, 11(1), 61-89.

Justino, M. V.; \& Tengeh, R. K. (2016). Role of external environmental factors in the failure of small enterprises in Angola. Business perspectives.org. Environmental Economics (open-access), 7(2). Vol. 7, Issue \#2.

Macedo, S. A. S.; Nóbrega, K. C.; Queiroz, J. V.; \& Whebber, P. (2012). Planejamento e gestão estratégica: um estudo sobre adoção e práticas em indústrias do Rio Grande do Norte. Revista Eletrônica Sistemas \& Gestão. Vol. 7, n. 1, pp. 58-75.

Machado, D. G.; Azevedo, T. P.; \& Silva, R. P. (2007). O impacto gerado pela tributação no empreendedorismo. Revista Contexto, Porto Alegre, v.7, n. 12.

Madruga, S. R.; Colossi, N.; \& Biazus, C. A. (2016). Funções e competências gerenciais do contador. ReA UFSM - Revista de Administração da UFSM. Santa Maria, v. 9, n. 2, p. 182191.

Matias, M. A.; \& Martins, G. A. (2012). Ações empreendedoras e manifestações cognitivas: um estudo com empresários contábeis de Minas Gerais. XXXVI Encontro da ANPAD. Rio de Janeiro/RJ.

Mayr, S.; Mitter, C.; \& Aichmayr, A. (2017). Corporate crisis and sustainable reorganization: evidence from bankrupt Austrian SMEs. Journal of Small Business Management. 55.

Michieletto, O. V.; Romão, J. G.; Urvanavicius, V.; \& Lima, E. O. (2010). Análise do modelo de direção de escritórios de contabilidade a partir das contribuições de Mintzberg sobre configurações. XIII Seminário de administração SEMEAD. São Paulo/SP.

Peleias, I. R.; Segreti, J. B.; Silva, G. P.; \& Chirotto, A. R. (2007). Evolução do ensino da contabilidade no Brasil: uma análise histórica. Revista Contabilidade e Finanças - USP, São Paulo, Edição 30 Anos de Doutorado, p. 19-32.

Peleias, I. R.; Castro Jr., F. H. F.; Cunha, M. L.; \& Segreti, J. B. (2011). Planejamento Estratégico em Organizações Contábeis na Cidade de São Paulo. REPeC - Revista de Educação e Pesquisa em Contabilidade, Brasília, v. 5, n. 1, art. 4, p.73-98.

Peleias, I. R.; Lourenço, R. A.; Peters, M. R. S.; \& Lavarda, C. E. F. (2015). Atributos do Desempenho Profissional na Visão de Empresários Contábeis da Grande São Paulo. REPeC - Revista de Educação e Pesquisa em Contabilidade, Brasília, v.9, n.2, art. 3, p. 160-181.

Pretorius, M. (2009). Defining Business decline, failure and turnaround: A content analysis.The Southern African Journal of Entrepreneurship and Small Business Management, 2(1), 1. 
Rodrigues, A.T.L; \& Lemos, I.S. (2009). Ferramentas de gestão para organizações contábeis. Porto Alegre: ConTexto, v. 9, n. 16.

Serviço de Apoio às Micro e Pequenas Empresas - Sebrae. (2016a). Sobrevivência das empresas no Brasil. Brasília: Sebrae.

Serviço de Apoio às Micro e Pequenas Empresas - Sebrae. (2016b). Pesquisa "relação das MPE com os contadores". Brasília: Sebrae.

Sithole, S. T. M. (2015). Quality in accounting graduates: Employer expectations of the Graduate skills in the bachelor of Accounting degree. European Scientific Journal August 2015 edition vol. 11.

Shonesy, L.; \& Gulbro, R. (1998). Small business success: a review of the literature. Annual Conference of Small, 1-17.

Testas, C. P.; \& Moreira, F. R. (2014). O empreendedorismo no ensino superior. Revista Gestão e Desenvolvimento, 22, 139-163.

Thornhill, S.; \& Amit, R. (2003). Learning About Failure: Bankruptcy, Firm Age, and the Resource-Based View. Organization Science, 14(5), 497-509.

Triviños, A. N. S. (1987). Introdução à pesquisa em ciências sociais: a pesquisa qualitativa em educação. São Paulo: Atlas.

Vale, G. M. V.; \& Guimarães, L. de O. (2010). Redes sociais, informação, criação e sobrevivência de empresas. Perspect. ciênc. inf. Belo Horizonte, v. 15, n. 3, p. 195- 215.

Zammel, M.; \&Khoufi, W. (2016). The Causes of Tunisian SME Failure. ArabianJournalof Business and, 6(6).

Yin, R. K. (2010). Estudo de caso: planejamento e métodos. 4. ed. Porto Alegre: Bookman.

Walter, S. A.; Cruz, A. P. C.; Espejo, M. S. B.; \& Gassner, F. P. (2009). Uma análise da evolução do campo de ensino e pesquisa em contabilidade sob a perspectiva de redes. Revista Universo Contábil, 5 (4), 76-93.

Walter, S. A.; Cruz, A. P. C.; \& Espejo, M. M. D. S. B. (2011). Análise do processo de gestão estratégica: um estudo comparativo em escritórios de contabilidade. Revista de Educação e Pesquisa em Contabilidade, 5(Especial), 45-76. 